\title{
Vanguardia, mística, rebeldía y sueños. Centenario de Luis Ortega Bru en el Palacio del Obispo (Málaga)
}

\author{
Vanguard, mysticism, rebellion and dreams. Centenary of Luis Ortega Bru in the
} Bishop's Palace (Málaga)

José Manuel Leiva Aldea

Departamento de Historia del Arte, Universidad de Málaga, España (joseleivaaldea@uma.es)

Recibido el 21 de Diciembre de 2016; revisado el 27 de Diciembre de 2016; aceptado el 9 de Enero de 2017; publicado el 1 de Marzo de 2017.

RESUMEN: Coincidiendo con el centenario del nacimiento de Luis Ortega Bru, (San Roque, Cádiz, 1916-1982) podremos conocer y profundizar en la obra heterogénea de este artista referente de la plástica española de la segunda mitad de la pasada centuria, tanto en sus variantes escultóricas y pictóricas como en temáticas religiosa y profana.

PALABRAS CLAVE: Exposición, Málaga, Escultura, Vanguardia, Tradición, Religión, Profano.

\begin{abstract}
Coinciding with the centenary of the birth of Luis Ortega Bru, San Roque (Cadiz, 19161982), we will be able to know and go in depth the heterogeneous work of this mentor artist to the spanish arts of the second half of the last century, both in its sculptural variants and pictorial, as in religious or secular subjects.
\end{abstract}

KEYWORDS: Exhibition, Málaga, Sculpture, Avant-Garde, Tradition, Religion, Secular.

Hasta finales de enero de 2017 podrá visitarse Ortega Bru. Vanguardia, mística, rebeldía y sueños en Ars Málaga, espacio de arte de esta diócesis. La muestra ha sido promovida y organizada por la Archicofradía Sacramental de la Pasión de Málaga, com la colaboración de diversas instituciones y empresas municipales, a la que se suman el Consistorio de San Roque y algunas cofradías de pasión de distintos puntos de la geografía andaluza. El comisariado y discurso museográfico corre a cargo del historiador del arte Javier González Torres, asesorado por un grupo heterogéneo de profesores universitarios.

La retrospectiva, enmarcada en los actos conmemorativos del centenario del nacimiento del artista sanroqueño, que se celebra en 2016, reúne casi un centenar de piezas, inéditas gran parte de ellas, con las que se pretende elaborar un discurso acerca de la modernidad de la poética de Ortega Bru, inmerso en un contexto poco favorable a la indagación en nuevas posibilidades artísticas de calidad. Como colofón de la misma, hay que destacar el ciclo de conferencias que estudia desde el punto de vista académico la figura del artista. 
"No puedo vender mi arte a los que solo quieren ver muñecos bonitos" es la frase lapidaria de Ortega Bru con la que se acoge al espectador en la exposición Vanguardia, mística, rebeldía y sueños. Esta declaración, que a priori podría "espantar'” a un grupo determinado de visitantes que creen que en la muestra encontrarán única y exclusivamente piezas de imaginería regidas por los cánones academicistas, barrocos y neo-barrocos que pueblan el territorio andaluz y su ámbito cofrade, sirve para hilvanar uno de los pilares de la narrativa argumental del recorrido. La elección de esta frase pretende que tomemos conciencia de la modernidad y vanguardia de Luis Ortega Bru dentro del panorama de la imaginería procesional andaluza y las manifestaciones plásticas en la España de la segunda mitad del s. XX.

El recorrido se organiza en torno a 4 secciones: El hombre, el artista, el esteta, el místico; Poéticas de lo moderno y lo imposible, Del sentimiento trágico de la vida: Espiritualidad y creación y El alma de la madera. Cada uno de estos capítulos se enmarcan dentro de un discurso que pretende dar a conocer los avatares de la vida del artista, su estilo inconfundible, su dominio de las diversas técnicas artísticas y conjugación de las plásticas de la pasada centuria con los valores del arte histórico, sobre todo los lenguajes del barroco.

\section{El hombre, el artista, el esteta, el místico}

El primer espacio ahonda en la presentación de Luis Ortega Bru como un artista polifacético y de producción heterogénea que se mueve por diversos puntos del territorio nacional (Málaga, Cádiz, San Roque, Madrid, Sevilla...), lo que le reportará otros puntos de vista e influencias estilísticas que plasmará en su obra artística, tanto religiosa como profana (escultura, pintura, dibujo...). Pero la proyección del sanroqueño no se limita a lo nacional, sino que traspasará nuestras fronteras. Una de sus piezas más significativas son las puertas que realiza para la Prelatura del Opus Dei (Roma, 1956), de las que podemos contemplar los vaciados en yeso en la exposición. Consta de 6 paneles rectangulares con escenas alusivas a algunas de las iconografías más relevantes de la tradición cristiana, como la Anunciación, Sagrada Familia o Piedad, entre otras. Pero, a la vez, vemos una serie de obras religiosas como la mencionada anteriormente, un Crucificado (1963-1965), una moderna Resurrección (1970-1975) o un boceto en barro de un Arcángel para la Hermandad de las Penas (Sevilla, 1979-1980).

Dos de las creaciones que más llaman la atención en esta sección fueron Motorista (VII) (1968) y Alegoría del Peñón de Gibraltar (1965) [1]. En estas obras podemos ver algunos de los puntos modernidad en la producción de Bru. La primera nos retrotrae a las primeras vanguardias históricas, concretamente al futurismo italiano y al cubo-futurismo ruso. A través de la sensación de dinamismo y velocidad, observamos el interés por evocar avances de la sociedad contemporánea (motociclismo) y el conferir valores estéticos a creaciones de ingeniería, Bru establece un paralelismo con obras de las poéticas mencionadas anteriormente como Dinamismo de un ciclista (Boccioni, 1913) o Ciclista (Natalia Goncharova, 1913) 


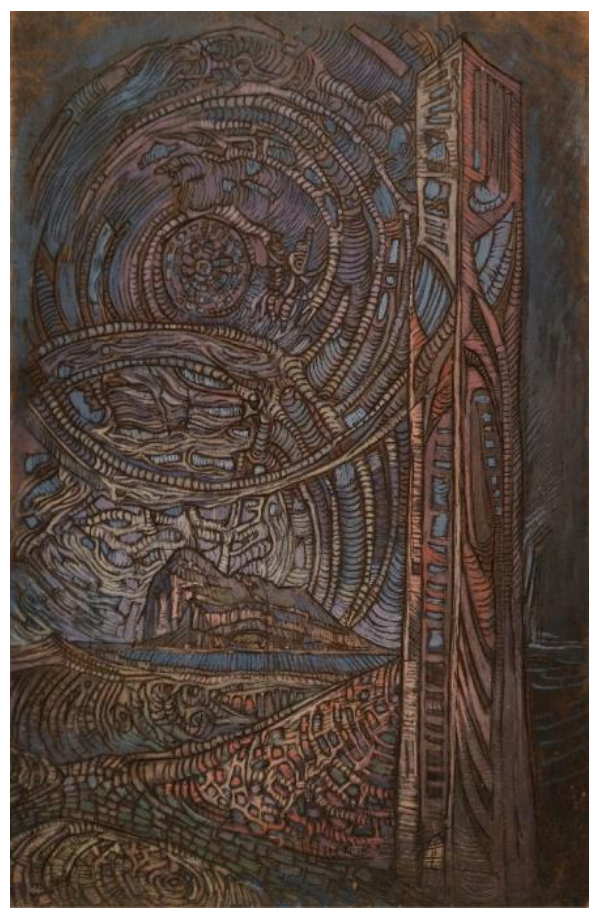

1. Alegoría del Peñón de Gibraltar, ca. 1965

\section{Poéticas de lo moderno y lo imposible}

Si el capítulo anterior nos presentaba una comunión entre las poéticas más clásicas y las tendencias del s. XX, en las producciones del artista, una segunda sección nos introduce aún más en las aportaciones a la plástica contemporánea del gaditano. Según el profesor Andrés Luque, las primeras indagaciones de Bru en las tendencias más actuales comienza en los años 50, en el inicio de una segunda etapa juvenil ya en Sevilla. En ella dio muestras de unas inquietudes inusuales en el contexto sevillano, sobre todo en lo que se refiere a la deformación de los modelos barrocos sevillanos con la influencia del expresionismo germano y, por otra parte, a la búsqueda de relaciones armónicas que le permitieron representar fragmentos de la realidad con una extraordinaria veracidad y expresarse con criterios propios con los que trascendió los principios naturalistas (Luque, 2016, pp. 53-54).

Mientras que el primer epígrafe pretendía visibilizar la heterogeneidad estilística y técnica de Bru, esta parte de la exposición se centra exclusivamente en las poéticas contemporáneas, como bien indica su título. Hacía alusión anteriormente al futurismo y al expresionismo como corrientes que influyen en el sanroqueño, pero podríamos establecer otros paralelismos, como la estrecha relación que guardan las aberturas u oquedades en diversas pinturas y esculturas como Pasaje fluvial II(19601965), La contemplación de lo infinito (1960-1965) [2], o Las Tres Gracias (1959). La abstracción también estará presente en este apartado, con algunas piezas destacadas como Composición abstracta. Madrid (II) (1975). 
El valor de estas obras, en el que pretende incidir este espacio radica en el contexto en que se realizan y la valentía que supone emplear ciertas poéticas que, aunque estuvieran más que desarrolladas en el panorama internacional, eran novedosas en el ámbito español, poco dado a la experimentación durante los 40 años de dictadura.

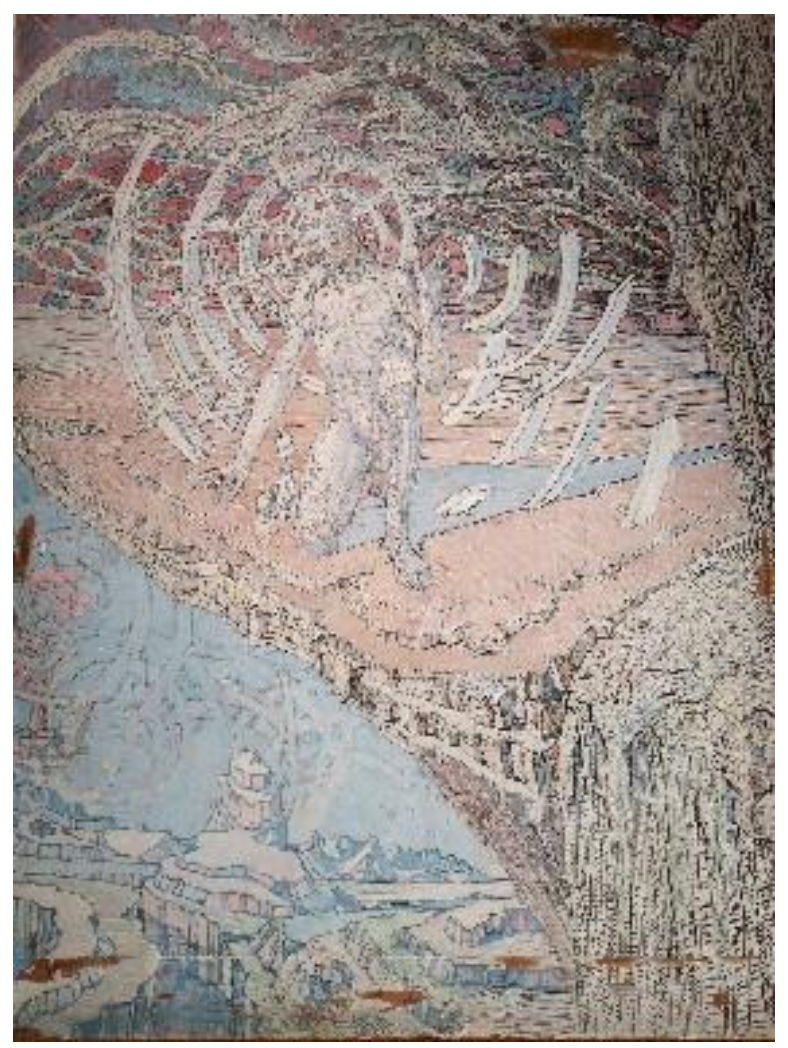

2. La contemplación de lo infinito, 1960-1965

\section{Del sentimiento trágico de la vida: espiritualidad y creación}

Este estilo personal y desgarrado del que venimos hablando no se habría 'configurado' de tal manera si Bru no hubiera padecido una serie de situaciones personales trágicas que harían de él una persona atormentada y con un fuerte pesar que arrastró durante toda su vida (muerte de amigos, asesinato de sus padres o represalias en un campo de concentración, entre otras situaciones dramáticas). A esto se complementa una religiosidad muy personal que le llevaba a realizar introspecciones en las que comparaba su dolor con los sufrimientos de Cristo durante su camino al Calvario.

Este desasosiego y pesar se transmitirán a sus obras de imaginería relacionándose con Cristo, como decía en el párrafo anterior, a través de una serie de bocetos en barro para diversas imágenes procesionales de hermandades andaluzas, destacando un poderoso busto de José de Arimatea (1978) de claras referencias miguelangelescas que realizó para la Hermandad del Descendimiento de Málaga. No obstante, y probablemente debido a la negativa de las juntas de gobierno de dichas cofradías, no se ha cedido el número de imágenes que habríamos deseado, siendo esta una de las carencias de las que 
adolece la muestra, perdiendo una oportunidad histórica que podría haber servido servido para reunir, a modo de comparativa, sus propuestas cultuales más relevantes. Los bocetos se acompañan de otras gráficas y pinturas que continúan la maniera de oquedades, tanto de temática profana como religiosa.

\section{El alma de la madera}

El último espacio de la exposición, exclusivo de imágenes religiosas, nos recibe con una disposición tan espectacular como predecible de la pieza capital de la muestra y una de las más interesantes de la producción de Ortega Bru, Jesús de la Pasión (1976-1977), realizado para la Archicofradía Sacramental de la Pasión (Málaga) [3]. Remarcamos el concepto de predecible ya que se ha aprovechado el anterior montaje con el que se presentó el Crucificado de la Misericordia del malagueño José María Ruiz Montes, expuesto hasta el pasado mes de noviembre en la muestra Misericordia. La imagen se sitúa en el centro de la sala, en total oscuridad, contrarrestada levemente por una luz cenital que remarca el carácter divino de la escultura. La fuerza de la efigie radica en la expresividad de sus ojos color miel, la potente zancada, los pliegues de la piel, sobre todo en los pies, y la boca, que parece infundirnos un hálito divino.

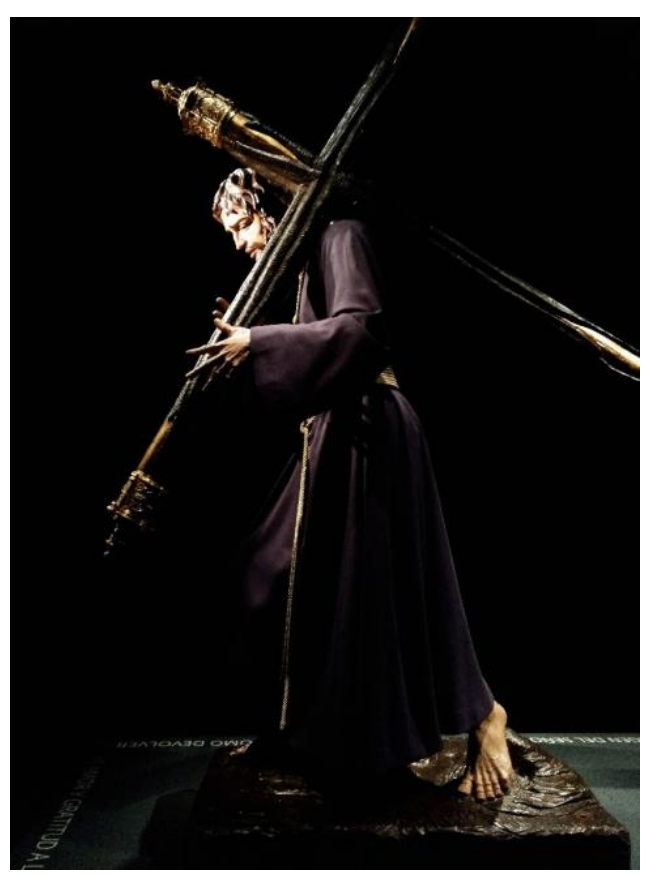

3. Jesús de la Pasión, 1976- 1977

El Nazareno de la Pasión para la corporación malacitana de su título es la síntesis de todo el arte de Luis Ortega Bru, al contener dentro de sí toda la fuerza 'olímpica' nacida de esa terribilitá miguelangelesca, que el visionario escultor sanroqueño tanto estudiaría y se esforzaría por hacer completamente suya (Sánchez López, 1996, p. 378).

Pero no será el nazareno el único interés de este espacio final. Tras atravesar la sala en penumbra, concluimos la exposición con una serie de piezas no menos interesantes, como un Arcángel confortador (1970) para la Hermandad del Huerto del Puerto de Santa María (Cádiz), Judas Iscariote 
(1976) de la Hermandad de la Sagrada Cena (Sevilla) o la Dolorosa de las Penas (1953) de la Hermandad de Santa Marta (1953), por mencionar algunas de las más relevantes.

\section{Conclusiones}

Con más luces que sombras (podría haber estado más nutrida respecto a tipología temática), Ortega Bru. Vanguardia, mística, rebeldía, sueños es una oportunidad excepcional para conocer las facetas más ignoradas de Luis Ortega Bru como artista polivalente, más allá de la típica y excluyente consideración de "imaginero". Gracias a la exposición, complementada con un ciclo de charlas y conferencias, el ámbito académico pretende ubicar al artista de San Roque en el puesto que se merece dentro del ámbito artístico español de vanguardia de la segunda mitad del s. XX.

\section{Referencias bibliográficas}

LUQUE TERUEL, Andrés (2016), “La relación con las vanguardias como medio de expresión', en GONZÁLEZ TORRES, Javier (com.), Ortega Bru. Vanguardia, mística, rebeldía, sueños. Centenario (1916-2016) (exposición celebrada en Málaga, Ars Málaga, del 2 de diciembre de 2016 al 28 de enero de 2017), pp.53-54, Archicofradía Sacramental de la Pasión y Ars Málaga, Málaga.

SÁNCHEZ LOPEZ, Juan Antonio (1996), "Escultura procesional en la Semana Santa de Málaga: Ensayo de catalogación', en El alma de la madera. Cinco siglos de iconografía y escultura procesional en Málaga, Hermandad de la Amargura, Málaga. 